\title{
The Value of Drug Stability Studies and Their Publication
}

\author{
Glen Brown
}

$\mathrm{T}$ The Canadian Journal of Hospital Pharmacy (CJHP) has a long history of publishing manuscripts that describe research into the stability of extemporaneously compounded medications. Canadian institutional pharmacists are fortunate that several of their colleagues have done extensive work in this field. The research laboratories of Ron Donnelly at The Ottawa Hospital, Dr Mary Ensom at the British Columbia Children's Hospital, and Scott Walker at Sunnybrook Health Sciences Centre have provided, through their articles in $C J H P$, much useful information that allows practitioners to understand what storage conditions are acceptable for drug formulations beyond the commercially available products. For example, this issue contains an article about the stability of an extemporaneous formulation of domperidone, ${ }^{1}$ and the Journal's Editorial Board continues to welcome such research for publication. But why?

The provision of drug therapy in a formulation that will allow the active therapeutic moiety to reach the targeted site of action is a basic necessity of treatment. However, for certain patient populations encountered in Canadian institutions, this foundational aspect of pharmacokinetics cannot be achieved with commercially available products. A common occurrence is the clinical scenario in which oral administration is desired, but the patient is unable to tolerate commercially available solid oral dosage formulations. This situation frequently arises with patients who are either very young or very old. For the very young, the required drug dosage may be so small, or the ability to swallow so unreliable, that commercially available dosage formulations are unrealistic or unsafe. ${ }^{2}$ Among elderly patients, the incidence of dysphagia is reportedly as high as 7\%-13\%, ${ }^{3}$ making utilization of available oral dosage formulations unfeasible or unsafe. Similarly, Canadian hospital pharmacists often encounter patients with oral, neck, or gastric cancer, which may make commercial solid dosage formulations impossible to use. ${ }^{4}$ For all of these populations, the hospital pharmacist may need to extemporaneously prepare alternative formulations that will allow the patient to receive the full benefit of the therapy. Another common scenario arises where topical therapy for a skin condition is warranted, because systemic drug administration is not desired owing to potential drug or disease interactions. In this situation, the pharmacist will want to explore the potential for preparing a topical product using a dosage formulation originally intended for oral administration. ${ }^{5}$

In all of the above scenarios, it is important to consider the efficacy and safety of the extemporaneously prepared product, and stability data supporting the specific formulation are desired. ${ }^{6,7}$ Infostab, a nonprofit organization based in France, has established a database listing published stability reports for extemporaneously prepared parenteral and enteral formulations, which may assist practitioners in preparing a needed product (www.stabilis.org). Stability studies published in CJHP appear in this database.

The CJHP continues to serve as a forum for publication of new information on the stability of extemporaneous products. These articles will assist Canadian pharmacists in complying with the compounding recommendations of the National Association of Pharmacy Regulatory Authorities. ${ }^{8-10}$

Stability studies submitted to CJHP for consideration must be based on appropriate methods, which will allow readers to have confidence in extrapolating the findings to their own practice. CJHP's "Information for Authors" includes information on the necessary description of materials, storage conditions, analytical techniques, and reproducibility. ${ }^{11}$ Additional guidelines on stability studies of parenteral products ${ }^{12}$ and anticancer drugs $^{13}$ are also available. Authors submitting manuscripts to CJHP are asked to comply with these compatibility guidelines ${ }^{12,13}$ for the specific drug formulation and intended route of administration described within their research. We also welcome inquiries from readers who are willing to serve as peer reviewers for research articles on the stability of extemporaneous formulations. The expertise of reviewers allows the Journal to maintain a high standard of quality for publications on this topic. 
Canadian practitioners continue to benefit from the new knowledge discovered through research into the stability of extemporaneously prepared products, and CJHP will continue to serve as a vehicle of dissemination for such new information.

\section{References}

1. Lingertat-Walsh K, Law S, Walker SE. Stability of extemporaneously compounded domperidone $5 \mathrm{mg} / \mathrm{mL}$ suspension in Oral Mix in plastic and glass bottles and plastic syringes. Can J Hosp Pharm. 2018;71(3):165-72.

2. Richey RH, Hughes C, Craig JV, Shah UU, Ford JL, Barker CE, et al. A systematic review of the use of dosage form manipulation to obtain required doses to inform use of manipulation in paediatric practice. Int J Pharm. 2017;518(1-2):155-66.

3. Logrippo S, Ricci G, Sestili M, Cespi M, Ferrara L, Palmieri GF, et al. Oral drug therapy in elderly with dysphagia: between a rock and a hard place! Clin Interv Aging. 2017;12:241-51.

4. Lam MSH. Extemporaneous compounding of oral liquid dosage formulations and alternative drug delivery methods for anticancer drugs. Pharmacotherapy. 2011;31(2):164-92.

5. Chiu HY, Tsai TF. Topical use of systemic drugs in dermatology: a comprehensive review. J Am Acad Dermatol. 2011;65(5):1048.e1-e22.

6. Prankerd RJ. Compounded products - stability studies in hospital pharmacy departments. J Pharm Pract Res. 2009;39(1):5-7.

7. Vigneron J. Stability studies: a scientific mission of the hospital pharmacist. Pharm Technol Hosp Pharm. 2017;2(4):143-4.

8. Model standards for pharmacy compounding of hazardous sterile preparations. Ottawa (ON): National Association of Pharmacy Regulatory Authorities; 2016 Oct [revised 2016 Nov; cited 2018 Jun 10]. Available from: http://napra.ca/sites/default/files/2017-09/Mdl_Stnds_Pharmacy_ Compounding_Hazardous_Sterile_Preparations_Nov2016_Revised_b.pdf

9. Model standards for pharmacy compounding of non-hazardous sterile preparations. Ottawa (ON): National Association of Pharmacy Regulatory Authorities; 2016 Oct [revised 2016 Nov; cited 2018 Jun 10]. Available from: http://napra.ca/sites/default/files/2017-09/Mdl_Stnds_Pharmacy_ Compounding_NonHazardous_Sterile_Preparations_Nov2016_Revised_b.pdf
10. Model standards for pharmacy compounding of non-sterile preparations. Ottawa (ON): National Association of Pharmacy Regulatory Authorities; 2018 [cited 2018 Jun 10]. Available from: http://napra.ca/sites/default/files/ documents/Mdl_Stnds_Pharmacy_Compounding_Nonsterile_Preparations_ March2018_FINAL.pdf

11. Policy for publication of chemical stability study manuscripts. Can J Hosp Pharm. 1990;43(1):3. Also available from: www.cjhp-online.ca/cshp/ templates/images/Stability_Guidelines.pdf

12. Hecq JD, Bihin B, Jamart J, Galanti L. Criteria for judging the quality of a publication on physicochemical stability of ready to use injectable drugs. Pharm Technol Hosp Pharm. 2017;2(2):79-84.

13. Bardin C, Astier A, Vulto A, Sewell G, Vigneron J, Trittler R, et al. Guidelines for the practical stability studies of anticancer drugs: a European consensus conference. Eur J Hosp Pharm. 2012;19(3):278-85.

Glen Brown, PharmD, FCSHP, BCPS(AQ), BCCCP, is with the Pharmacy, St Paul's Hospital, Vancouver, British Columbia. He is also an Associate Editor with the Canadian Journal of Hospital Pharmacy.

Competing interests: None declared.

\section{Address correspondence to:}

Dr Glen Brown

Pharmacy

St Paul's Hospital

1081 Burrard Street

Vancouver BC V6Z 1 Y6

e-mail: gbrown@providencehealth.bc.ca

\section{ON THE FRONT COVER}

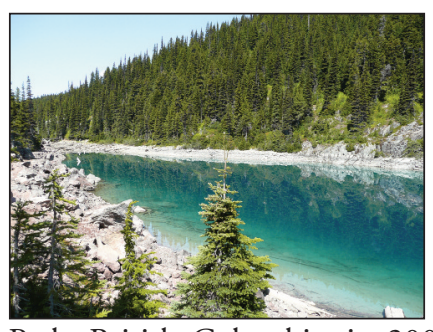

\section{Garibaldi Lake, British Columbia}

Robin Ensom took this photo (using a Panasonic DMC-TZ3 camera) while hiking with his wife, Mary, in Garabaldi Provincial Park, British Columbia, in 2009. The hike was part of a July 1st weekend getaway that also included a couple of nights in Whistler and some horseback riding in the BC interior. Both Robin, a former president of the Canadian Society of
Hospital Pharmacists (CSHP), and Mary, a former editor of the Canadian Journal of Hospital Pharmacy, have been deeply involved in pharmacy practice and education throughout their careers. Their respective contributions have been recognized through the CSHP Distinguished Service Award, granted to Robin in 2009 and to Mary in 2018.

The CJHP would be pleased to consider photographs featuring Canadian scenery taken by CSHP members for use on the front cover of the Journal. If you would like to submit a photograph, please send an electronic copy (minimum resolution $300 \mathrm{dpi}$ ) to publications@cshp.ca. 